\title{
ASSOCIATION BETWEEN POLLUTION CAUSED BY VEHICULAR EMISSION AND DEVELOPMENT OF RESPIRATORY DISEASES AMONG TRAFFIC POLICE PERSONNEL OF PESHAWAR CITY
}

\author{
Waseeq Ullah', Sohaila Ikram², Nazia Shahana ${ }^{3}$ \\ 1. Khyber Poly Clinic Hospital \\ 2. Lady Reading Hospital \\ 3. Khyber Teaching Hospital
}

\section{ABSTRACT:}

\section{OBJECTIVE:}

The study aims to find the association between pollution caused by vehicular emission and development of respiratory diseases among traffic police personnel in Peshawar, Khyber Pakhtunkhwa, Pakistan. There is no doubt that pollution has damaged the environment but the victim is not the environment only.

\section{METHODOLOGY:}

The study included and focused on two variables; one was independent and the other was dependent variable. Therefore, an effort has been made in this research to investigate and evaluate the relationship among the two variables i.e. pollution (independent) and development of respiratory disease (dependent). A questionnaire was distributed among 250 traffic personnel but only 154 became the part of this study because the study included only nonsmokers. The questionnaire consisted of 27 questions which comprised of open ended and closed ended questions.

\section{RESULTS:}

After gathering the data, correlation was run over the data to find the relationship. It found that there was a positive and significant relationship between pollution emission by vehicles and development of respiratory diseases.

\section{CONCLUSION:}

Therefore, hypothesis 1 was accepted and the null hypothesis was rejected.

\section{KEYWORDS: Pollution, Vehicular Emission, Respiratory Diseases}

\section{INTRODUCTION:}

The development of mankind through the process of migration, known as urbanization, has brought many problems for the people and the environment itself. These problems have a direct

\begin{tabular}{|c|c|}
\hline $\begin{array}{c}\text { Correspondence } \\
\text { Waseeq Ullah } \\
\text { House No: 148, St: 7, Sector: F4 } \\
\text { Phase-6, Hayatabad, Peshawar } \\
\text { Email: dr.waseeq091@gmail.com } \\
\text { Phone: 0333-9888016 }\end{array}$ & $\begin{array}{l}\text { effect on human } \\
\text { health, which has } \\
\text { been a victim to } \\
\text { the results of } \\
\text { urbanization. }\end{array}$ \\
\hline
\end{tabular}

The major problem that has taken place due to urbanization is the pollution that increases day by day due to the activities of people living in certain locality ${ }^{1}$. There are several types of pollution but the one which is more threatening and damaging the human health is the air pollution that contains harmful gases like Sulphur oxides, organic compound, nitrogen oxide and carbon monoxide. Collectively these gases are harmful for not only 
human beings but every other living organism that lives in the world ${ }^{2}$. Medically it's proven that those substances that are less than ten microns are very harmful for human health because they get accumulated in human lungs, which can result in various serious illnesses that can be fatal in some cases $^{3}$. The issue of air pollution has not been only harmful for human life but it has serious impacts on the environment as well, for instance the deterioration of ozone layer, which has also been a cause of global warming and in extreme situation it has been the cause for skin cancer in many areas of the world ${ }^{4}$.It appears that majority of the death rate in urban areas are due to air pollution which results in various lungs and other diseases that are very harmful to human life. A lot of road blockages and security check posts created by the security personnel have added to this problem. These problems result in extra fuel consumption and delay. This paper suggests planning and development of a properly maintained and monitored traffic system and ways to discourage the private vehicles owned by the people in large numbers ${ }^{5}$. These air pollutants are the results of human inventions for their benefit and to live a comfortable life but these inventions and machinery has increased the level of pollution in the air. These results in the burning of fuel which is a poison to the environmental air that is being breath by the people living in those areas. There is a term usually used to address the air pollution as PM, which means combination of different matters that constitute the oxides of nitrogen and Sulphur that is generated through the burning of fuels and friction of vehicle tire of an automobile. Such activities add or increase the level of air pollution in areas where there are a lot of vehicles and transport activities occurance ${ }^{1}$. The present study focuses on the relationship among the pollution which results from the vehicle emission and the disease especially respiratory that occurs in the traffic police of Peshawar region.

\section{METHODOLOGY:}

The present study will include Peshawar urban regions where the research will include the population and draw its respective sample to compete the study by collecting data from the traffic police. This will include areas starting from Gulbahar (city side) till Hayatabad (phase seven). The aim is to cover as many policemen to be the part of this study. This will help the researcher to get as many answers as possible to the questions that were to be asked from the traffic police. Peshawar is a thickly populated area and people possess vehicles that consumes petrol, diesel and compressed natural gas, equally contributing to air pollution. In such situation the traffic police are almost all day on the roads to control the traffic in the city. Therefore, this research will open a new dimension to control the air pollution. This will give a clear message to concerned authorities that serious steps are needed to improve conditions to control the air pollution and to reduce the chances of lungs and other illnesses. The study will try to find the association of the pollution that results from the emission of vehicles and the respiratory diseases among the traffic police in Peshawar region. The main objective is to identify the relationship among the two main variables of the study. This study will help to identify the links between the respiratory disease and the air pollution. The air pollution is Peshawar is mainly because of the combustion of fuels in the vehicles used by people. These gases are to be controlled to control the pollution. Unfortunately, there has been no successful measure to control the traffic and pollution. The present study will be an alarm to higher authorities that it is not only messing with the environmental issues, but it is also damaging human health especially of those traffic police who are trying to control the uncontrollable traffic of Peshawar and playing with their lives for the betterment of the society. The methodology of the study includes the collection of primary data. The population includes all the traffic police personnel working in the entire Peshawar region. The study included 250 individuals which were calculated among the population working as traffic police at various check posts and on road starting from Gulbahar (city side) till Hayatabad (phase seven). The sample size is drawn by keeping 95 percent confidence interval 


\section{RESULTS:}

Simple random sampling technique was used to collect the data for the study to find the association between the two variables. Primary data is only required for the analysis of the study. The collection of data required to develop a questionnaire which includes the two variables in detail and some medical background of the sample. For that purpose, a questionnaire was designed which included a total of 37 questions which were close ended, while some were open ended. In order to check the validity and reliability of the data collection tool, a pilot test was conducted to improve the weakness, which was improved and errors were removed from the questionnaire. The research required 3 months for its completion. This included developing a proposal, a base of different work of other researchers. Furthermore, it required to develop a questionnaire and collect data from the respective people to achieve the objectives of the study. Data was collected once from the respective individuals. Only those police personnel were included who were performing duties as the traffic police in Peshawar and were non-smokers. No other police personnel from any other department will be a part of this study. The data collected undergo a correlation test to find the association among the variables of the study. After analysis data was interpreted along with respective tables. The major hurdle faced by the researcher was that the traffic police were very busy during their duty time and it was hard to ask them to fill the questionnaire. Therefore, the researchers tried to ask questions one by one and it took them a lot of time to gather data from the traffic police. The data included 250 respondents, but the problem was that only the data from nonsmokers were included, otherwise the result would be incorrect. Therefore, out of 250 respondents only 154 traffic personnel $(61.6 \%)$ were non-smokers as illustrated in Table 1. Table 2 shows the standard deviation, mean and variance of the data. As in Table 3, which interprets the correlation, shows the relationship between pollution emitted by vehicles and development of respiratory diseases among traffic police personnel to be positive, because of the positive value of Pearson's that is 0.960 , which is near to 1 and the relationship is significant, as the value of significance is less than .05. Therefore, it approves hypothesis1, and hence $\mathrm{H} 1$ is accepted. The present study undertakes the following two variables;
Independent Variable

Pollution from the emission of vehicles
Dependent Variable

Development of respiratory diseases

Table 1: Traffic Personnel

\begin{tabular}{|c|c|c|c|c|c|}
\hline \multicolumn{3}{|c|}{ Frequency } & Percentage & Valid Percentage & $\begin{array}{c}\text { Cumulative } \\
\text { Percentage }\end{array}$ \\
\hline \multirow{3}{*}{ Valid } & Non-Smokers & 154 & 61.6 & 61.6 & 61.6 \\
\cline { 2 - 6 } & Smokers & 96 & 38.4 & 38.4 & 100 \\
\cline { 2 - 6 } & Total & 250 & 100 & 100 & \\
\hline
\end{tabular}


Table 2: Descriptive Statistics $(n=154)$

\begin{tabular}{|c|c|c|c|c|c|}
\hline & Min & Max & Mean & $\begin{array}{c}\text { Std. } \\
\text { Deviation }\end{array}$ & Variance \\
\hline Do you have cough? & 1 & 2 & 1.19 & .392 & .154 \\
\hline $\begin{array}{l}\text { Do you think your cough have been caused by } \\
\text { something your breath in at work? }\end{array}$ & 1 & 2 & 1.55 & .500 & 250 \\
\hline $\begin{array}{l}\text { At any time in the last } 12 \text { months have you been woken } \\
\text { at night by an attack of shortness of breath? }\end{array}$ & 1 & 2 & 1.59 & .493 & .243 \\
\hline $\begin{array}{l}\text { Have you ever experienced wheezing or whistling } \\
\text { during duty hours? }\end{array}$ & 1 & 2 & 1.68 & .467 & .218 \\
\hline Do you have any allergies? & 2 & 2 & 2.00 & .000 & .000 \\
\hline $\begin{array}{l}\text { Does your department provide you with protective } \\
\text { equipment like face masks? }\end{array}$ & 1 & 2 & 1.45 & .499 & .249 \\
\hline If yes, do you use this equipment regularly? & 1 & 2 & 1.16 & .370 & .137 \\
\hline $\begin{array}{l}\text { Thinking about your chest symptoms as a whole in the } \\
\text { last } 12 \text { months, what happened to them when you were } \\
\text { away from work for a week or longer? }\end{array}$ & 1 & 4 & 1.37 & .863 & .744 \\
\hline $\begin{array}{l}\text { Thinking about your chest symptoms as a whole in the } \\
\text { last } 12 \text { months, what happened to them on working days } \\
\text { compared to non-working days? }\end{array}$ & 3 & 3 & 3.00 & .000 & .000 \\
\hline
\end{tabular}

Table 3: Correlation Test Interpretation $(n=154)$

\begin{tabular}{|c|c|c|}
\hline & Pollution & Respiratory Diseases \\
\hline Pearson Correlation & 1 & .960 \\
\hline Sig. (1-tailed) & .002 & .002 \\
\hline
\end{tabular}

\section{DISCUSSION:}

These components can be promised to be a source of study in developing the strategies in development of systems to cope with these respiratory problems ${ }^{6}$. A small amount of data available on the topic suggests that the indoor pollution (smoking, PM combustion etc.) and outdoor pollution such as traffic can be the reasons that lead to developing chronic obstructive pulmonary disease (COPD) ${ }^{7,8}$. On the other hand, the present study showed that people were not allergic to anything, which may have been the cause for the respiratory disease such as coughing, asthma and wheezing etc. They were provided by the safety instruments such as mask but those were not effective that's why some of them did not wear those at the time of duty. They reported that they suffered from asthmatic attack sometimes, and experience shortness of breath at times. They also confirmed that they suffered chest wheezing sometimes, especially at night. Majority of them confirmed that when they were away from their routine duties they felt better. That was because they were not inhaling the polluted air which they must on the roads at day or night time during their duty shifts. It was also confirmed by the respective traffic personnel that they felt even worse when they were sick, and they must perform their duties. The results showed a positive and significant relation among the variables. 


\section{CONCLUSION:}

The following study was very important in terms of public health sector. It focused on an issue which the society is not so aware of. The air pollution especially generating from the vehicles which people are operating in the region of Peshawar has contributed not only to increase the environmental issue but it has drastically increased the respiratory disease in this region. It included only those traffic personnel who were performing their duties on the main road and they were nonsmokers. It included 250 sample from Peshawar region traffic police but 154 qualified to become the subject of the study because other 96 people were doing regular smoking. After the data was collected, the researchers tested the hypothesis by running correlation over the data to find the association among the pollution and respiratory diseases. The result showed that there was positive and significant relation among the variables. Therefore hypothesis 1 was accepted and the null hypothesis was rejected based on the analysis. The researchers proposed the following factors to be studied and included in the future research work to increase the body of knowledge in this field related to the issue. The research should add those individuals as well whose job requires driving on the road most of the times. Especially the drivers who are working in the transportation industry and taxi drivers as well. The research should increase the scope of the report and include as many cities since it will give a clear and broader picture of the problems and an idea about the seriousness of this issue. The research should involve government personnel and the concerned department to understand the intensity of the problem and come up with a solution to improve human health and control the air pollution generated from the emission of the vehicles. The government should take corrective measure to control the pollution at local level by introducing some system to control the vehicles which generate more smoke in the environment and makes the system more effective.

\section{REFERENCES:}

1. Shah S, Cocker D, Miller JW, Norbeck JM. Emission rates of particulate matter and elemental and organic carbon from in use diesel engines. Environ Scientific Technological. 2004;38:2544-50.

2. Rield M, Diaz-Sanchez D. Biology of diesel exhaust effects on respiratory function. J Allergy Clin Immunol. 2005;115:221-28

3. Cotes JE. Lung function: assessment and application in medicine. 4th ed. Melbourne: Blackwell Scientific Publication; 1978.

4. Balmes $\mathrm{J}$. The role of ozone exposure in the epidemiology of asthma. Environ Health Perspective. 1993;101:219-24.

5. Ali Z, Shah S, Hussain A. Growing traffic in Peshawar: an analysis of causes and impacts. South Asian Studies. 2012;27(2):1026-678.

6. Ko FWS, Hui DSC. Air pollution and chronic obstructive pulmonary disease. Respirology. 2012;17:395-401.

7. Dominici F, Sheppard L, Clyde M. Health effects of air pollution: a statistical review. Int Stats Rev. 2003 Aug;71(2):243-76.

8. Ingle ST, Pachpande BG, Wagh ND, Patel VS, Attarde SB. Exposure to vehicular pollution and respiratory impairment of traffic policemen in Jalgaon City, India. Industrial Health. 2005;43(4):656-62. 